\title{
Candida albicans Induces Metabolic Reprogramming in Human NK Cells and Responds to Perforin with a Zinc Depletion Response
}

\author{
Daniela Hellwig ${ }^{1 \dagger}$, Jessica Voigt ${ }^{1 \dagger}$, Maria Bouzani ${ }^{2}$, Jürgen Löffler ${ }^{2}$, \\ Daniela Albrecht-Eckardt', Michael Weber', Sascha Brunke ${ }^{4}$, Ronny Martin', \\ Oliver Kurzai ${ }^{*}$ and Kerstin Hünniger ${ }^{1}$
}

\begin{abstract}
${ }^{1}$ Septomics Research Center, Leibniz Institute for Natural Product Research and Infection Biology - Hans Knoell Institute and Friedrich Schiller University, Jena, Germany, ${ }^{2}$ Medizinische Klinik und Poliklinik II, Universitätsklinikum Würzburg, Würzburg, Germany, ${ }^{3}$ BioControl Jena GmbH, Jena, Germany, ${ }^{4}$ Department Microbial Pathogenicity Mechanisms, Leibniz Institute for Natural Product Research and Infection Biology - Hans Knoell Institute, Jena, Germany
\end{abstract}

OPEN ACCESS

Edited by:

Agostinho Carvalho,

University of Minho, Portugal

Reviewed by:

Mihai Netea,

Radboud University Nijmegen Medical

Center, Netherlands

Ricardo Silvestre,

University of Minho, Portugal

*Correspondence:

Oliver Kurzai

oliver.kurzai@leibniz-hki.de

tThese authors have contributed equally to this work.

Specialty section: This article was submitted to Fungi and Their Interactions,

a section of the journal

Frontiers in Microbiology

Received: 10 December 2015

Accepted: 03 May 2016

Published: 19 May 2016

Citation:

Hellwig D, Voigt J, Bouzani M, LöfflerJ, Albrecht-EckardtD,

WeberM, BrunkeS, Martin R,

Kurzai $O$ and HünnigerK (2016)

Candida albicans Induces Metabolic Reprogramming in Human NK Cells and Responds to Perforin with a Zinc

Depletion Response.

Front. Microbiol. 7:750.

doi: 10.3389/fmicb.2016.00750
As part of the innate immune system, natural killer (NK) cells are directly involved in the response to fungal infections. Perforin has been identified as the major effector molecule acting against many fungal pathogens. While several studies have shown that perforin mediated fungicidal effects can contribute to fungal clearance, neither the activation of NK cells by fungal pathogens nor the effects of perforin on fungal cells are wellunderstood. In a dual approach, we have studied the global gene expression pattern of primary and cytokine activated NK cells after co-incubation with Candida albicans and the transcriptomic adaptation of $C$. albicans to perforin exposure. NK cells responded to the fungal pathogen with an up-regulation of genes involved in immune signaling and release of cytokines. Furthermore, we observed a pronounced increase of genes involved in glycolysis and glycolysis inhibitor 2-deoxy-D-glucose impaired C. albicans induced NK cell activation. This strongly indicates that metabolic adaptation is a major part of the NK cell response to $C$. albicans infections. In the fungal pathogen, perforin induced a strong up-regulation of several fungal genes involved in the zinc depletion response, such as $P R A 1$ and $Z R T 1$. These data suggest that fungal zinc homeostasis is linked to the reaction to perforin secreted by NK cells. However, deletion mutants in PRA1 and ZRT1 did not show altered susceptibility to perforin.

Keywords: Candida albicans, NK cells, perforin, glycolysis, zinc

\section{INTRODUCTION}

Natural killer (NK) cells are $\mathrm{CD} 56^{+} \mathrm{CD} 3^{-}$cytotoxic lymphocytes of the innate immune system. These cells exert important antiviral and antitumoral activity by killing virus-infected or cancerous cells. Major effector mechanisms are the release of transmembrane pore forming perforin and granzyme B or induction of death receptor-mediated apoptosis (Lanier, 2008). Activation of NK cells is controlled by activating and inhibiting germline-encoded receptors. Classically, activation by virus-infected or cancerous cells occurs via missing self-signaling, i.e., the absence of constitutively expressed markers like MHC class I on the surface of target cells that results in 
abrogation of signaling by inhibiting receptors and thus a dominance of activating signals (Lanier, 2008). In addition, activating receptors may recognize pathogen or cell stressinduced ligands (Martinet and Smyth, 2015). Accumulating evidence suggests that NK cells are directly involved in the response to fungal infections (Schmidt et al., 2013). Beside data from murine models, indicating that NK cells are required for full protection against Aspergillus fumigatus, Cryptococcus neoformans and - depending on the immunological status Candida albicans, patients with a NK cell defect due to primary hemophagocytic lymphohistiocytosis are predisposed to fungal infection (Lipscomb et al., 1987; Sung et al., 2001; Morrison et al., 2003; Albisetti et al., 2004; Li et al., 2013; Quintin et al., 2014). NK cells exhibit direct antifungal activity against $C$. neoformans and enhance clearance of this pathogen in vivo (Lipscomb et al., 1987; Levitz et al., 1994; Ma et al., 2004; Schmidt et al., 2013). The antifungal activity against $C$. neoformans is mainly mediated via perforin (Ma et al., 2004). In addition to C. neoformans, antifungal activity of $\mathrm{NK}$ cells has also been demonstrated for Paracoccidioides brasiliensis, Coccidioides immitis, Rhizopus arrhizus (Rhizopus oryzae), A. fumigatus and C. albicans (Jimenez and Murphy, 1984; Petkus and Baum, 1987; Bouzani et al., 2011; Schmidt et al., 2011, 2015; Voigt et al., 2014). We and others have shown that human NK cells are activated by $A$. fumigatus and show fungicidal activity against this mold pathogen. The molecular mechanisms are not yet fully understood but evidence suggests that beside perforin, also IFN- $\gamma$ may contribute to fungal damage (Bouzani et al., 2011; Schmidt et al., 2011). C. albicans has been shown to activate NK cells in a contact dependent manner, which may even result in phagocytic uptake of the fungal pathogen (Voigt et al., 2014). C. albicans mediated activation of NK cells triggers degranulation of secretory granules and the release of several cytokines including IFN- $\gamma$ and TNF- $\alpha$. Furthermore, NK cells show immunomodulatory potential in alliance with neutrophilic granulocytes (Voigt et al., 2014). Recently, NKp30 has been identified as a receptor for fungal pathogens on human NK cells (Li et al., 2013). Perforin also appears to be the major mediator of anti-Candida activity in human NK cells (Voigt et al., 2014). Taken together, studies performed with different fungal pathogens and both human and murine NK cells indicate that perforin is the major antifungal effector of NK cells. Perforin is stored in secretory granules of cytotoxic lymphocytes and can be released into an immunological synapse. In the target cell membrane, perforin oligomerizes and forms large transmembrane pores, which penetrate and damage the target cell membrane. In perforin-granzyme mediated cell death, granzyme enters the target cell via these pores and initiates apoptosis in the target cell (Voskoboinik et al., 2015).

To further elucidate the interaction of human NK cells and $C$. albicans, we performed an array-based analysis of the transcriptional response of $\mathrm{NK}$ cells after confrontation with C. albicans as well as of $C$. albicans after exposure to perforin. Transcriptome analyses have provided fundamental insights into host pathogen interaction: the response of pathogens to host cells and tissue offers insight into the mechanisms required to invade the host and successfully evade host immunity. On the other hand the transcriptional response of host cells to infection enables the identification of cellular defense mechanisms and patterns of activation (Waddell et al., 2007). Our results show that beside functional activation of human NK cells, C. albicans also induces an activation-specific metabolic shift, namely enhanced glycolytic activity. The exposure of $C$. albicans to perforin triggered a narrow set of regulated genes. Most importantly, perforin induced a prototypic zinc depletion response. Despite this, deletion of genes essential for zinc acquisition did not alter effects of perforin on C. albicans.

\section{MATERIALS AND METHODS}

\section{Fungal Strains and Culture Conditions}

The C. albicans wildtype strain SC5314 (Gillum et al., 1984) and the mutants pra1s (ura3:: imm434/ura3:: imm43, his1::hisG/his1::hisG, pra1::HIS1/pra1::ARG4+CIp10, Citiulo et al., 2012) and zrt1s (ura3:: imm434/ura3:: imm434, his1::hisG/his1::hisG, zrt1::HIS1/zrt1::ARG4+CIp10, Citiulo et al., 2012) were used in this study. For co-incubation with NK cells, strains were cultured overnight in standard YPD medium (1\% yeast extract, 2\% bacto-peptone, 2\% D-glucose) at $30^{\circ} \mathrm{C}$ and diluted $1: 10$ in fresh medium for a $1.5 \mathrm{~h}$ induction culture at $30^{\circ} \mathrm{C}$ on a shaker prior to the experiments. Harvested cells were washed three times in PBS and resuspended in Stem Cell Growth Medium (SCGM, Cell Genix) + 10\% human serum (PAA). To obtain C. albicans filaments, cells were grown overnight in M199 medium (9.8 g/l M199, 35.7 g/l HEPES, $\left.2.2 \mathrm{~g} / \mathrm{NaHCO}_{3}\right), \mathrm{pH} 4$ at $37^{\circ} \mathrm{C}$ to stationary phase in a shaking incubator. Fungal cells were then reseeded in M199 medium, pH 8 and cultured for approximately $1 \mathrm{~h}$ at $37^{\circ} \mathrm{C}$, which induced filamentous growth in C. albicans. Filaments were killed by incubation in $0.1 \%$ thimerosal (Sigma-Aldrich) in HBSS at $37^{\circ} \mathrm{C}$ for $1 \mathrm{~h}$ and then rinsed extensively. For co-incubation of C. albicans with perforin, fungi were suspended in RPMI1640 (Biochrom) containing 5\% heat-inactivated FBS (Sigma-Aldrich) or SD-N-acetyl-D-glucosamine media [0.67\% YNB w/o amino acids (Sigma-Aldrich), $2 \% \mathrm{~N}$-acetyl-D-glucosamine] to a final concentration of $4 \times 10^{4}$ cells $/ \mathrm{ml}$. $100 \mu \mathrm{l}$ per well were seeded into lumitrac 96-well plates (Greiner). Hyphal induction occurred in the absence (control) or presence of different perforin concentrations (Enzo, isolated from YT cell line) for $1-8 \mathrm{~h}$ at $37^{\circ} \mathrm{C}$ and $5 \% \mathrm{CO}_{2}$. Concentrations of perforin ranged from 100 to $500 \mathrm{ng} / \mathrm{ml}$.

\section{Human Natural Killer Cells}

Primary human PBMCs were isolated from the buffy coat of healthy donors by standard Ficoll gradient centrifugation (Biochrom AG). Untouched NK cells were separated by MACS technology using the NK cell isolation kit (Miltenyi Biotec) according to manufacturer's instructions. Purity of the cells was checked by FACS analysis with results of $>95 \% \mathrm{CD}^{+} 6^{+}, \mathrm{CD} 6^{+}$, $\mathrm{CD}^{-}, \mathrm{CD}^{-} 4^{-} \mathrm{NK}$ cells. Freshly isolated human NK cells were cultivated at a concentration of $2 \times 10^{6} / \mathrm{ml}$ in $1 \mathrm{ml}$ Stem Cell Growth Medium (SCGM; Cell Genix) containing 10\% human serum (PAA) and $100 \mathrm{U} / \mathrm{mL}$ interleukin-2 (IL-2, Immunotools) in 24 well plates. Primary NK cells were used at day 1 after 
isolation. To generate cytokine activated NK cells, half of the medium was replaced after 3 days of cultivation by fresh SCGM containing $10 \%$ human serum supplemented with $100 \mathrm{U} / \mathrm{ml} \mathrm{IL}$ -

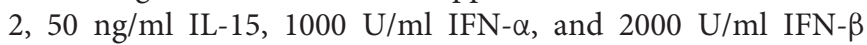
(Immunotools) and cultivated for another 3 days. This study was carried out in accordance with the Declaration of Helsinki. All protocols involving human blood donors were approved by the local Ethics Committee (permit number: 3639-12/12).

\section{Confrontation Assay}

Natural killer cells were either co-cultured with C. albicans yeasts at a MOI of 0.5 for $4 \mathrm{~h}$ (fungal viability assay, XTT assay) or at a MOI of 1 for 3 and $6 \mathrm{~h}$ (transcriptome analysis) at $37^{\circ} \mathrm{C}$ and $5 \% \mathrm{CO}_{2}$ in SCGM medium containing $10 \%$ human serum in reaction tubes. For glycolysis inhibitor treatment, NK cells were pre-incubated with $100 \mathrm{mM}$ 2-deoxy-D-glucose (2-DG, SigmaAldrich) for $30 \mathrm{~min}$ at $37^{\circ} \mathrm{C}$ and $5 \% \mathrm{CO}_{2}$ and further treated with $100 \mathrm{mM}$ 2-DG during confrontation with thimerosal-killed C. albicans filaments (MOI of 0.5 ) for $4 \mathrm{~h}$.

\section{Flow Cytometry}

Expression of NK cell surface markers was analyzed via differential FACS staining and subsequent measurement with the FACSCanto II (BD). Changes in surface expression were investigated for $\mathrm{Fc} \gamma$ receptor III (mouse anti-human CD16-APC, clone 3G8) and degranulation marker CD107a (mouse antihuman CD107a-PE, clone H4A3) as described previously (Voigt et al., 2014).

FlowJo 7.6.4 software was used for analysis.

\section{Quantification of Secreted Proteins}

The concentrations of secreted proteins within the supernatant of confrontation samples were determined using Luminex technology [MILLIPLEX MAP Human CD8+ T Cell Magnetic Bead Panel (Perforin, GM-CSF, IFN- $\gamma$, TNF- $\alpha$ ); Millipore]. The analysis was performed according to the instructions from the manufacturer.

\section{Fungal Viability Assay}

Killing of C. albicans was determined by XTT assay. C. albicans in medium alone (control) and NK cell - Candida co-cultures were washed with cold $\mathrm{ddH}_{2} \mathrm{O}$ and $0.2 \%$ Triton $\mathrm{X}$ to disrupt the immune cells and Candida cells were pelleted by centrifugation at $14.000 \times g$ for $5 \mathrm{~min}$ at $4^{\circ} \mathrm{C}$. Afterwards, the fungal cell pellet was resuspended in a solution of $0.5 \mathrm{mg} / \mathrm{ml} \mathrm{XTT} \mathrm{(Sigma-}$ Aldrich) heated at $55^{\circ} \mathrm{C}$ in $\mathrm{PBS}$ for $30 \mathrm{~min}$ and supplemented with $50 \mu \mathrm{g} / \mathrm{ml}$ Coenzyme Q (Sigma-Aldrich). Following an incubation step of $1 \mathrm{~h}$ at $37^{\circ} \mathrm{C}$, the absorption of the cell-free supernatant was measured at $450 \mathrm{~nm}$ wavelength (reference at $650 \mathrm{~nm}$ ). The fungal killing was calculated according to the formula: percentage of killing $=(1-\mathrm{X} / \mathrm{Y}) \times 100 . \mathrm{X}$ stands for the absorption of the different culture conditions and $\mathrm{Y}$ for the absorption of C. albicans in medium alone (control, set to $100 \%$ ).

\section{Microscopy and Image Analysis}

After fixation [Histofix (Roth), 4\%] and washing with PBS (Biochrom) fungal cells were stained with Calcofluor white
(Sigma) for $10 \mathrm{~min}$ and washed three times with PBS. Images were taken with a Zeiss LSM780 confocal microscope and hyphal length and averaged relative fluorescence intensities were analyzed with ZEN 2012 software.

\section{Transcriptome Analysis of NK Cells}

RNAprotect cell reagent (Qiagen) was added 1:5 to the experiments and samples were stored at $-80^{\circ} \mathrm{C}$ for further treatment. RNA isolation was performed with RNAeasy Mini Kit (Quiagen) following the manufacturer's instructions. RNA amplification and cRNA transcription was done with Illumina TotalPrep RNA Amplification Kit (Illumina) following the manufacturer's instructions. HumanHT-12 v4 Expression BeadChip Kits (Illumina) were used for transcriptome analyses. After quality control, arrays were preprocessed using $\mathrm{R}$ software version 2.14.1 ${ }^{1}$. Data were normalized using quantile normalization and logarithm. Probes were used only if they were present on at least three chips. A linear model was fit to the normalized data resulting in one normalized intensity value per transcript and chip. Transcripts were regarded as being significantly differentially expressed when they showed an absolute fold change of larger than 2 between at least two different conditions and an FDR adjusted $t$-test $p$-value of less than 0.05 . Differentially regulated transcripts were categorized according to KEGG using $\mathrm{DAVID}^{2}$. Microarray raw data are available at Array Express (http://www.ebi.ac.uk/arrayexpress/ and accession number E-MTAB-4105).

\section{Transcriptome Analysis of C. albicans}

The isolation of fungal RNA was done as described previously (Martin et al., 2011). Sample RNAs were labeled with Cy5CTP and hybridized with a Cy3-labeled common reference RNA on C. albicans DNA microarrays (ClinEuroDiag, Brussels, Belgium). The slides were hybridized, washed and scanned with a Genepix 4000B (Molecular Devices) as described in a previous study (Martin et al., 2011). Arrays were preprocessed using $\mathrm{R}$ software version $2.14 .1^{1}$ after a quality control. Normalization of the data was performed with Print-tip loess and Gquantile methods. A linear model was fit to the normalized data. Transcripts were only regarded as being significantly differentially expressed when they showed an absolute fold change of larger than 2 and an FDR-adjusted $t$-test $p$-value $\leq 0.05$. For qRT-PCRs, $100 \mathrm{ng}$ of total RNA were utilized with Brilliant III Ultra Fast SYBR Green qRT PCR Kit (Agilent Technologies). Expression analysis was performed on an Applied Stratagene Mx3005P (Agilent Technologies) and calculated by the $\Delta \Delta \mathrm{Ct}$ method (Pfaffl, 2001). Primers used in this study are shown in Supplementary Table S1. Microarray raw data are available at Array Express (http://www.ebi.ac.uk/arrayexpress/ and accession number E-MTAB-4109).

\section{Statistical Analyses}

For all experiments, at least three independent replicates using NK cells from non-identical donors or C. albicans cells from

\footnotetext{
${ }^{1}$ http://www.r-project.org

${ }^{2}$ http://david.abcc.ncifcrf.gov/
} 
non-identical cultures, respectively were used. Data are presented as arithmetic mean \pm standard deviation (SD) and statistical significance was calculated using a two-sided Student's $t$-test for unpaired data, shown as ${ }^{*} p<0.05,{ }^{* *} p<0.01$.

\section{RESULTS}

\section{Transcriptional Dynamics of Primary and Cytokine Activated NK Cells during Interaction with C. albicans Reveal Functional and Metabolic Activation}

In previous analyses, cytokine activated NK cells had been used for confrontation with $C$. albicans due to their potential use in immunotherapy (Voigt et al., 2014). To quantify the effect of cytokine induced activation, we measured the inhibitory potential of both primary and cytokine activated NK cells on C. albicans metabolic activity. Only slight changes in metabolic activity of $C$. albicans could be observed in the presence of primary NK cells, while cytokine primed NK cells reduced fungal metabolic activity by $32 \% \pm 10 \%$ (Figure 1, Voigt et al., 2014). To get a more detailed view on the differences between primary and cytokine activated $\mathrm{NK}$ cells during $C$. albicans confrontation, we investigated transcriptomic changes induced by $C$. albicans infection in both cell types. For this, primary and cytokine activated NK cells from three independent donors (three biological replicates) were co-incubated with C. albicans, harvested after 3 and $6 \mathrm{~h}$ of infection and analyzed on an Illumina HumanHT-12 v4 Expression BeadChip. Upon comparison of gene expression of NK cells confronted with C. albicans to that of mock-treated cells, a significantly higher number of genes was differentially regulated in cytokine primed NK cells, indicating a faster and more intense response compared to the primary cells (Figure 2; Supplementary Table S2). After $3 \mathrm{~h}$ of coincubation, 92 genes were differentially regulated in primary $\mathrm{NK}$ cells, whereas 285 genes were differentially regulated in cytokine activated NK cells. At 6 h of infection these numbers increased to 347 genes (primary NK cells) and 595 genes (cytokine activated NK cells), respectively (Figure 2; Supplementary Table S2). A comparison of gene expression of both NK cell types revealed a core transcriptional response of 204 genes toward C. albicans that were differentially regulated in cytokine activated and primary NK cells (Supplementary Table S2). Pathway analysis revealed differential regulation of genes involved in processes like immune cell signaling pathways, cytokine-cytokine receptor interaction and glycolysis (Table 1). Genes involved in cellular signaling pathways were among the most up-regulated genes especially in cytokine activated NK cells. A prominent example is the MAPK signaling pathway, known to be a major cascade in innate immune activation. A closer look at the genes involved in the MAPK signaling pathway highlights a more rapid and more intense response of cytokine activated NK cells as the transcriptional regulation of the central regulator MYC is higher in comparison to primary NK cells (Supplementary Table S2). Strong up-regulation of the phosphatases DUSP2, 4, 5, and 6

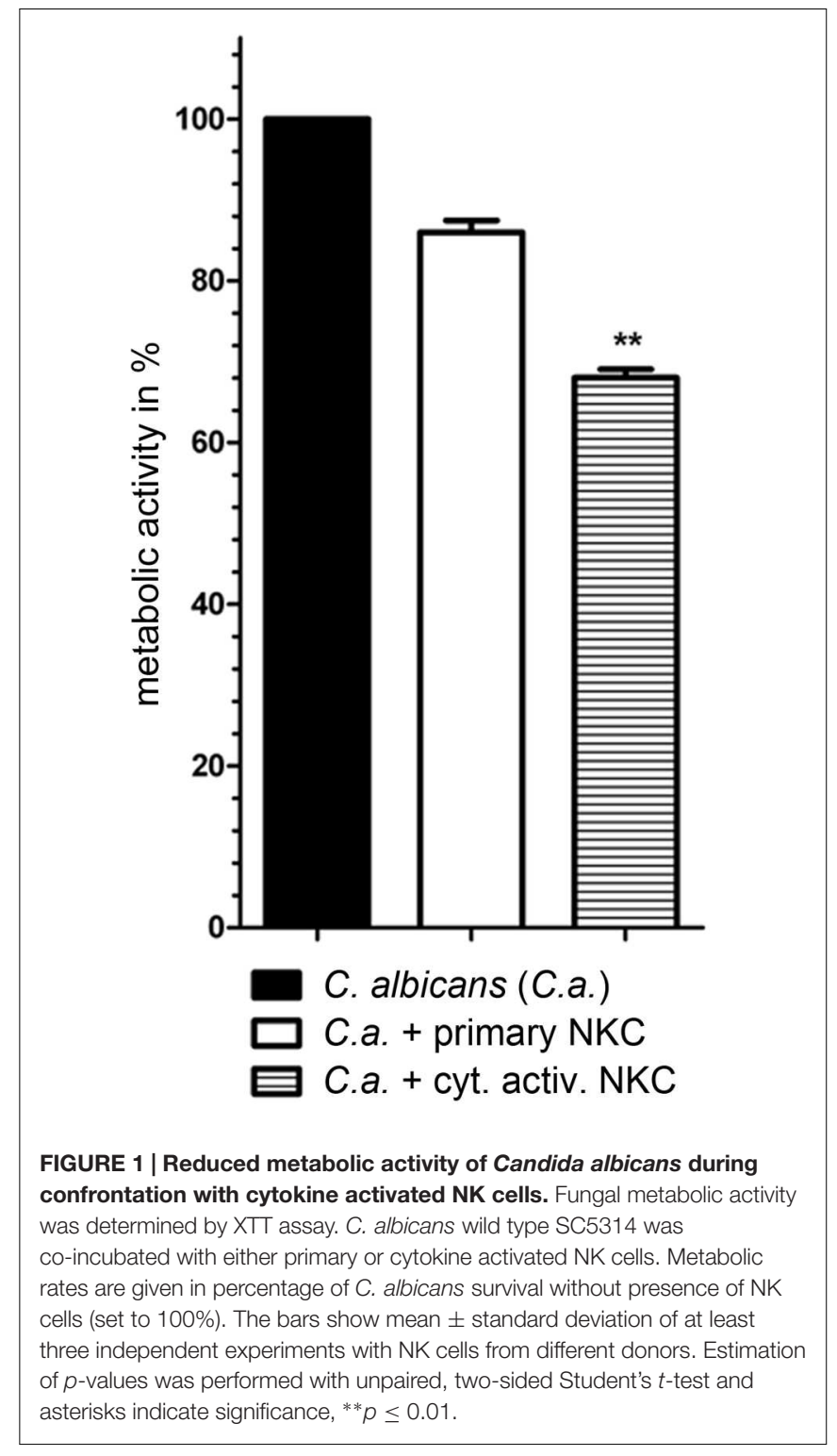

indicates the necessity of down-regulation of MAPK signaling cascade due to strong activation.

\section{Cytokine/Chemokine Signaling}

Important pro-inflammatory cytokines and chemokines have been quantified in the supernatant of cytokine activated NK cells after confrontation with $C$. albicans wild type in our previous study (Voigt et al., 2014). Here, the corresponding genes could be analyzed for their transcriptional regulation. Indeed, significant up-regulation of genes encoding for GMCSF (CSF2), IFN- $\gamma$, MIP-1 $\beta$ (CCL4) in primary and cytokine activated NK cells could be detected on the transcriptomic level (Figure 3). In addition to this and among several other chemokine and cytokine encoding genes (Figure 3; Table 1), the genes for IL8, involved in recruitment and activation of neutrophils (Duggan et al., 2015), CCL14, a homolog of CCL4 known to activate monocytes (Schulz-Knappe et al., 1996) and 

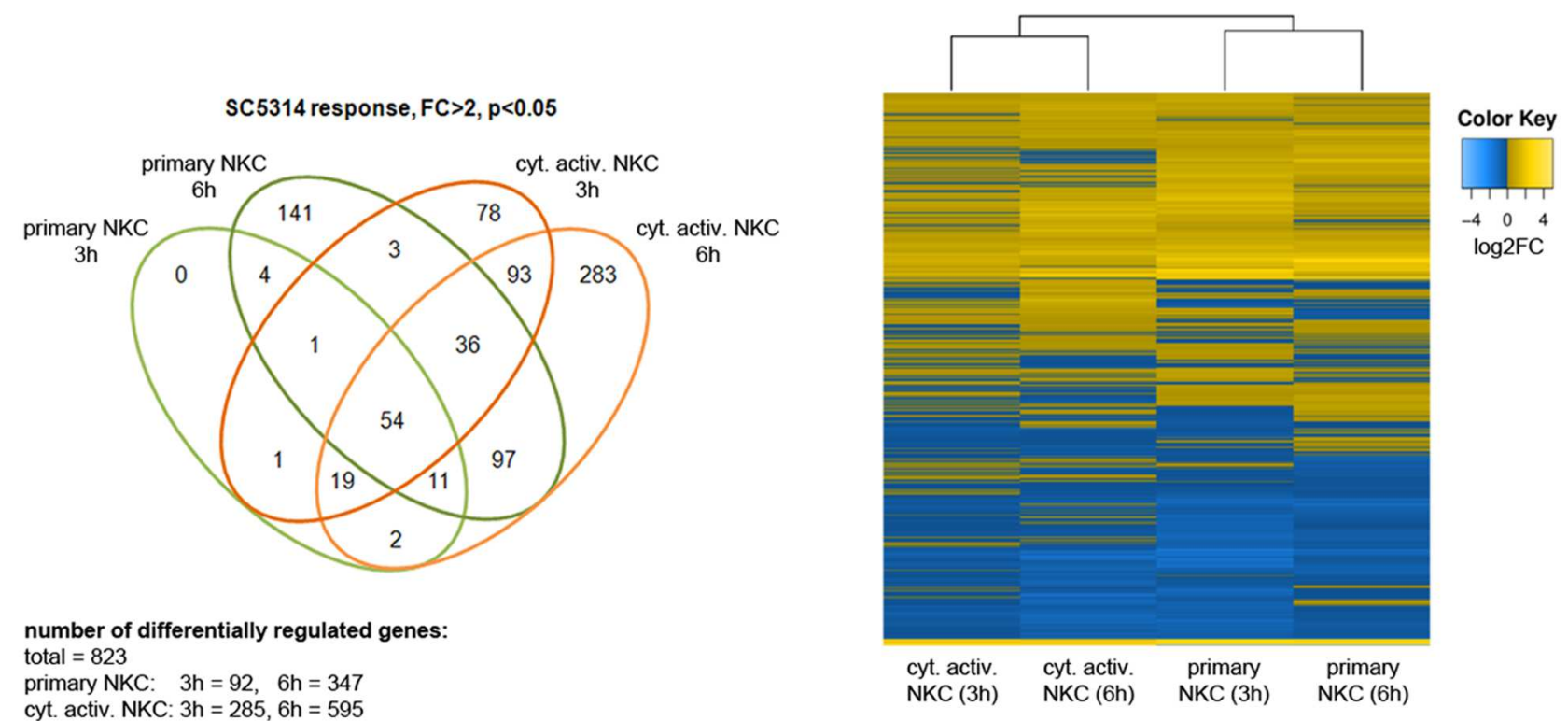

number of differentially regulated genes:

total $=823$

primary NKC: $\quad 3 \mathrm{~h}=92, \quad 6 \mathrm{~h}=347$

cyt. activ. NKC: $3 h=285,6 h=595$

NKC (3h) NKC (6h) NKC (3h) NKC (6h)

FIGURE 2 | Transcriptomic response of NK cells to C. albicans. Prior to RNA isolation, primary and cytokine treated NK cells were incubated with C. albicans wild type for 3 and $6 \mathrm{~h}$. We performed three independent experiments with NK cells from different donors. Venn diagram and heat map show the differentially expressed genes with a minimum absolute fold change $|\mathrm{FC}|$ of 2 in two different conditions $(p<0.05)$.

$\mathrm{XCL1}$, an activator of antigen-presenting dendritic cells (XCR1 ${ }^{+}$ subpopulation) and promoter of a Th1 response (Lei and Takahama, 2012), were strongly up-regulated, further extending the important role of NK cells as modulators of other immune cells. This modulatory function is also demonstrated by the induction of the pre-prohormone of adrenomedullin (ADM; see Supplementary Table S2), which after proteolytic cleavage exerts several functions, including vasodilation and antimicrobial activity against several bacterial pathogens (Elsasser and Kahl, 2002).

\section{Glycolysis}

A shift to aerobic glycolysis has been described as a metabolic hallmark of NK cell activation (Donnelly et al., 2014). In our data, we observed an up-regulation of several genes involved in glycolysis (Figure 4). These genes were either up-regulated in both types of NK cells or in cytokine activated NK cells only (Supplementary Table S2). Within the category glycolysis, the hexokinase 2 encoding gene $\mathrm{HK} 2$, one of the key rate limiting enzymes in glycolysis, was the most up-regulated gene (Supplementary Table S2). In addition, other important checkpoints in glycolysis, namely phosphofructokinase (gene PFKP up-regulated in primary and cytokine activated NK cells at $6 \mathrm{~h}$ post-infection) and lactatedehydrogenase (gene LDHA, up-regulated in primary and primed NKC at $3 \mathrm{~h}$ and $6 \mathrm{~h}$ ) were upregulated. Furthermore two bifunctional kinases/phosphatases that regulate the concentration of the glycolytic byproduct and activator of phosphofructokinase fructose-2,6-bisphosphate (PFKFB3, PFKFB4) were strongly up-regulated in primary and cytokine activated NK cells. Taken together, these data suggest a strong metabolic reprogramming of NK cells toward glycolysis after contact with $C$. albicans. To determine the contribution of glycolysis to NK cell antifungal activity, NK cells were treated with the glycolysis inhibitor 2-deoxy-D-glucose (2-DG) throughout infection with $C$. albicans. Since 2-DG was found to significantly diminish $C$. albicans filamentation in media alone (data not shown) and filamentation is a prerequisite for NK cell activation, glycolysis inhibitor assays were performed using thimerosal-killed C. albicans filaments. Incubation of NK cells with 2-DG clearly prevented CD16 down-regulation and significantly reduced the secretion of perforin and GM-CSF by NK cells after contact with $C$. albicans (Figure 5). In addition, TNF- $\alpha$ level in response to C. albicans was reduced after 2-DG treatment, although this effect was not statistically significant. The effects of 2-DG treatment were specific, as increased surface exposure of degranulation marker CD107a and release of IFN- $\gamma$ induced by C. albicans showed the same patterns in the absence or presence of 2-DG and were therefore not affected by the glycolysis blockage.

\section{Perforin Inhibits Filamentation of C. albicans in a Time and Dose Dependent Manner}

Transcriptome data for NK cells confronted with C. albicans confirmed strong metabolic and functional activation of these immune cells. However, they did not reveal potential novel fungicidal effector mechanisms. Our previous studies have suggested that perforin is a major mediator of NK cell mediated anti-C. albicans activity (Voigt et al., 2014). To further analyze the effects of human perforin to hyphal growth, C. albicans yeast cells were incubated in the presence of different concentrations of human perforin. After 1-8 h fungal cells were fixed and 
TABLE 1 | KEGG categories significantly overrepresented in differently expressed genes of primary and cytokine activated NK cells (NKC) challenged with Candida albicans.

\begin{tabular}{|c|c|c|c|c|}
\hline KEGG & Term & \# of genes & $p$-value & Genes \\
\hline \multicolumn{5}{|c|}{ (A) Primary and cytokine activated NKC (core response). } \\
\hline Hsa00010 & Glycolysis/gluconeogenesis & 7 & 0.00014 & $\begin{array}{l}\text { LDHA, PGAM4, ALDOC, } \\
\text { PGAM1, HK2, ENO2, PFKP }\end{array}$ \\
\hline Hsa04060 & $\begin{array}{l}\text { Cytokine-cytokine receptor } \\
\text { interaction }\end{array}$ & 13 & 0.00017 & $\begin{array}{l}\text { CSF2, IL3, IL8, IL21R, CCL4L1, } \\
\text { TNFSF9, CCL4, CCL14, } \\
\text { CCL3L1, CX3CR1, IFNG, } \\
\text { VEGFA, XCL1 }\end{array}$ \\
\hline \multicolumn{5}{|c|}{ (B) Primary NKC specific response. } \\
\hline Hsa04062 & Chemokine signaling pathway & 5 & 0.020 & $\begin{array}{l}\text { CXCL1, CCL3, IL8, CCR1, } \\
\text { PRKACB }\end{array}$ \\
\hline \multicolumn{5}{|c|}{ (C) Cytokine activated NKC specific response. } \\
\hline Hsa04110 & Cell cycle & 10 & 0.0015 & $\begin{array}{l}\text { E2F2, CDKN1A, GADD45G, } \\
\text { TTK, CDK6, CDC20, CDC25C, } \\
\text { GADD45B, MYC, CDC25B }\end{array}$ \\
\hline Hsa04010 & MAPK signaling pathway & 15 & 0.0018 & $\begin{array}{l}\text { PRKCA, TNF, MAP2K3, } \\
\text { FASLG, NR4A1, CDC25B, } \\
\text { DUSP5, DUSP4, DUSP2, } \\
\text { NTRK1, MAP3K8, GADD45G, } \\
\text { GADD45B, MYC, DUSP6 }\end{array}$ \\
\hline Hsa00010 & Glycolysis/gluconeogenesis & 6 & 0.0095 & $\begin{array}{l}\text { GPI, PKM2, HK1, PGK1, } \\
\text { GAPDHL6, ALDH3A2 }\end{array}$ \\
\hline Hsa04650 & $\begin{array}{l}\text { Natural killer cell mediated } \\
\text { cytotoxicity }\end{array}$ & 8 & 0.0255 & $\begin{array}{l}\text { PRKCA, ICAM1, CD244, TNF, } \\
\text { PIK3CD, NFAT5, FASLG, } \\
\text { NFATC1 }\end{array}$ \\
\hline Hsa04060 & $\begin{array}{l}\text { Cytokine-cytokine receptor } \\
\text { interaction }\end{array}$ & 12 & 0.02686 & $\begin{array}{l}\text { CCL1, LIF, TNFRSF9, TNF, } \\
\text { TNFRSF12A, CLCF1, CXCL16, } \\
\text { TNFSF14, FASLG, CCL4L2, } \\
\text { KIT, LTA }\end{array}$ \\
\hline
\end{tabular}

morphology was analyzed microscopically. Although C. albicans yeast cells started to form germ tubes independent of perforin concentrations during the first hour of incubation, a significant reduction of hyphal length was observed after $4 \mathrm{~h}$ with perforin concentrations of 250 and $500 \mathrm{ng} / \mathrm{ml}$ compared to filaments grown without the substance (Figures 6A,B). For the lowest perforin concentration $(100 \mathrm{ng} / \mathrm{ml})$ tested this delay of hyphal elongation started after $5 \mathrm{~h}$ of treatment. Growth reduction increased with duration of hyphal induction. After $8 \mathrm{~h}$ filament lengths were reduced to $71 \%$ by $100 \mathrm{ng} / \mathrm{ml}, 45 \%$ by $250 \mathrm{ng} / \mathrm{ml}$, and to $31 \%$ by $500 \mathrm{ng} / \mathrm{ml}$ perforin. Growth reduction correlated with morphology alterations showing swollen hyphal tips in the presence of perforin (Figure 6A, white arrows). To check if this observation was specific for serum-induced filamentous growth hyphal formation of $C$. albicans was additionally induced by $N$-acetylglucosamine containing media. A similar reduced elongation of $C$. albicans filaments as well as the swollen morphology by perforin could be observed under this condition (Figure 6C). Consequently, our results suggest that NK cell induced growth retardation of $C$. albicans was mainly mediated by perforin in a time- and concentration-dependent manner.

\section{The Transcriptional Response of C. albicans to Perforin}

To identify the cause of morphological alteration and delay of hyphal elongation induced by perforin, the genome wide expression profile of C. albicans after exposure to this substance was analyzed by whole genome DNA microarrays. Fungal cells were incubated with or without $500 \mathrm{ng} / \mathrm{ml}$ perforin followed by RNA isolation at different time points. In total, only a limited set of genes showed differential expression in response to the addition of perforin: 110 genes after $2 \mathrm{~h}, 112$ genes after $4 \mathrm{~h}$ and 93 genes after $8 \mathrm{~h}$ of perforin treatment (Figure 7A). Out of them, twelve genes were differentially expressed at all three time points, nine of those were up- and three were down-regulated. The response to perforin compromised the up-regulated genes DDR48, RTA2, PRA1, ZRT1, XOG1, orf19.6840, orf19.7214, orf19.4531, orf19.6601 and the down-regulated genes CHT2, orf19.2317, and orf19.4450.1 (Figures 7A,B; Supplementary Table S3). Expression patterns for four of these genes (PRA1, RTA2, CHT2, and orf19.4450.1) were verified by quantitative RT-PCR (Figure 7C).

\section{Perforin Selectively Induces a Zinc Starvation Response in C. albicans}

An interesting pattern was observed for genes involved in the maintenance of zinc homestasis in C. albicans. PRA1 and ZRT1 were found to be up-regulated during all time points with an increasing expression over time (Figure 7B; Supplementary Table S3). Both genes do not only share the same promoter, but were also shown to be important for sequestration of extracellular zinc ions (Citiulo et al., 2012). 


\section{cytokine gene expression}

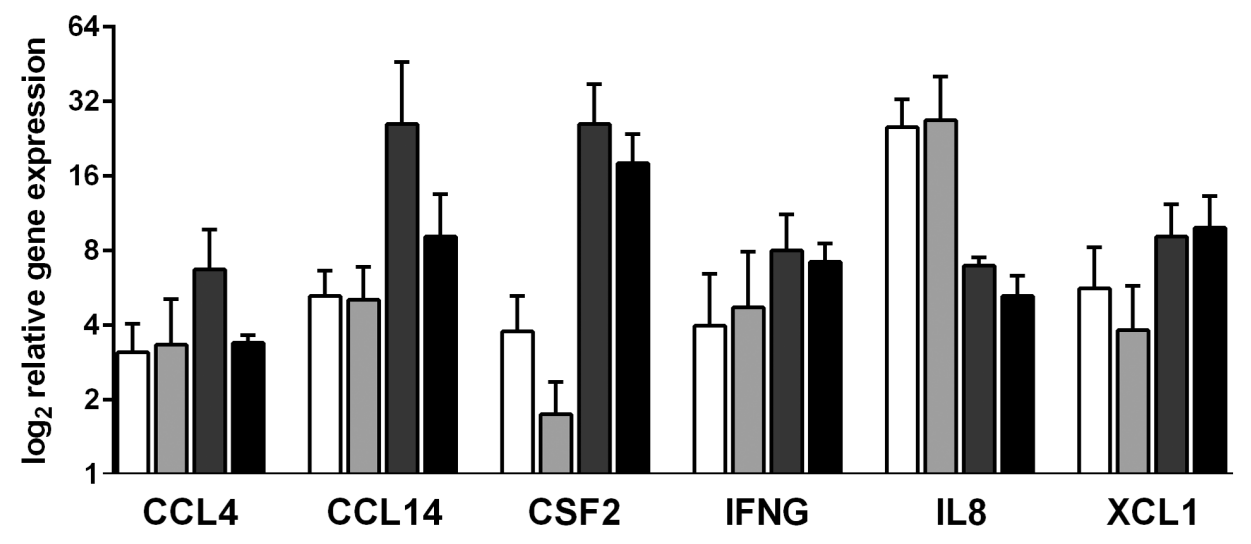

primary NKC (3h) $\square$ primary NKC (6h) $\square$ cyt. activ. NKC (3h) $\square$ cyt. activ. NKC (6h)

FIGURE 3 | Enhanced expression of cytokine genes in C. albicans infected NK cells. Changes in transcript levels of cytokine genes are detected during co-incubation of primary and cytokine activated NK cells with C. albicans for 3 and $6 \mathrm{~h}$. Data are displayed as fold change of $C$. albicans-treated cells relative to mock-treated cells ( $F C>2, p<0.05)$.

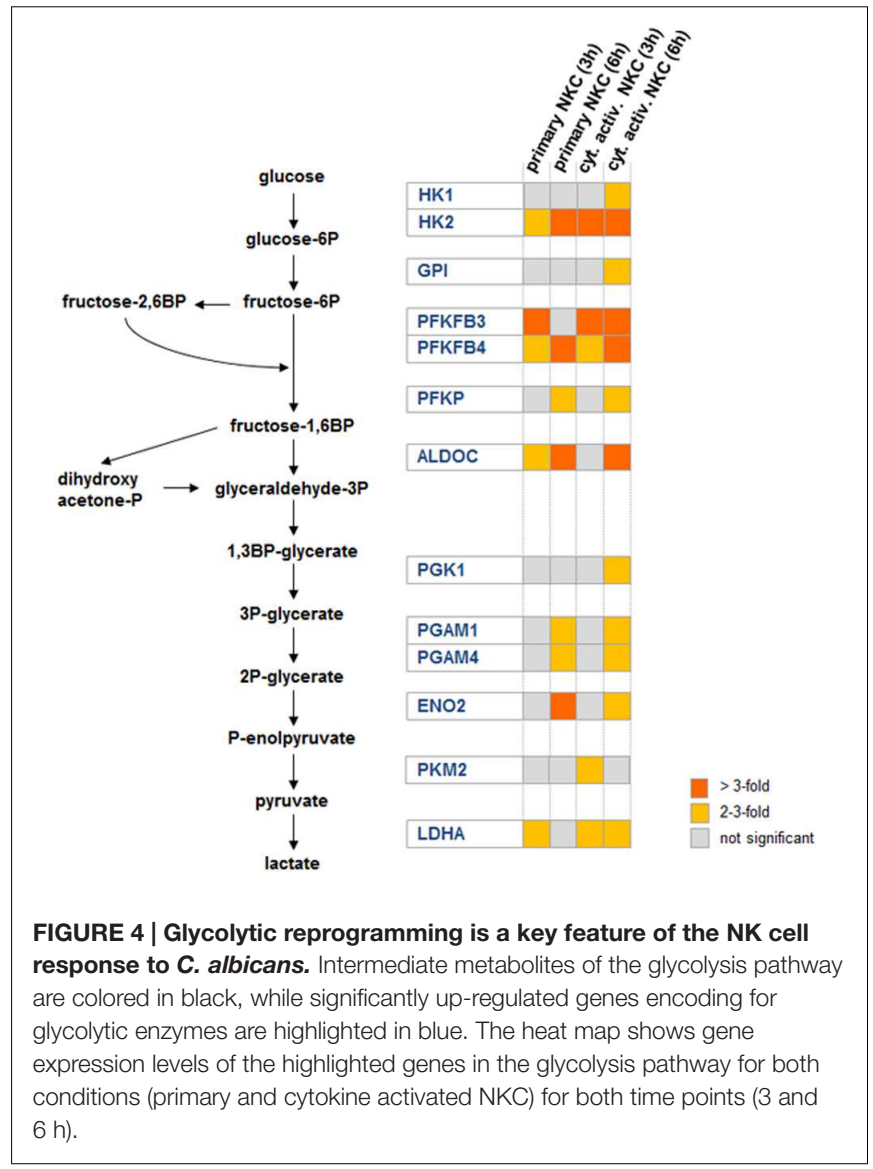

We have also observed an up-regulation of a second zinc transporter encoded by ZRT2 at $4 \mathrm{~h}$ and $8 \mathrm{~h}$ time points (Figure 7B; Supplementary Table S3). At the $8 \mathrm{~h}$ time point, we noticed an additional up-regulation of the putative C. albicans ZRT3 ortholog orf19.1534. The expression increase of these genes indicates that perforin might negatively influence zinc homeostasis in C. albicans. However, mutants lacking either PRA1 or ZRT1 showed the same hyphal elongation delay during perforin treatment as wild type filaments (Figure 7D). Due to the findings for zinc homeostasis, we looked for changes in transcriptomic responses involved in either calcium or iron homeostasis. Except for a slight up-regulation of the calcineurinregulated transcription factor gene $C R Z 1$ at the $2 \mathrm{~h}$ time point (Supplementary Table S3) we did not observe clear changes for calcium maintenance. Regarding iron homeostasis, we noticed an up-regulation of the low iron-induced ferric reductase gene FRE10 at $4 \mathrm{~h}$, but genes which are normally increased under high iron conditions like orf19.2452 or UCF1 were also up-regulated at the same time point (Supplementary Table S3). However, genes associated with iron utilization from heme and hemoglobin were partially up-regulated. This group included CSA1, CSA2, PGA10, and RBT5 (Figure 7B), with CSA2 being even strongly up-regulated at the $8 \mathrm{~h}$ time point with a more than eightfold increase.

\section{NK Cells Do Not Suppress Expression of the Core Filamentation Response in C. albicans}

Additionally, we noticed differential regulation of genes involved in cell wall remodeling. The exo-1,3- $\beta$-glucanase gene XOG1 was up-regulated during all time points (Figure 7B Supplementary Table S3). The same pattern was observed for a yet uncharacterized gene, orf1.7214, which is putatively encoding a glucan-1,3- $\beta$-glucosidase (Figure 7B; Supplementary Table S3), indicating that perforin influences the assembly of 1,3 - $\beta$-glucans within the fungal cell wall. On the other hand, the chitinase encoding gene CHT2 was always down-regulated. 
A

CD16

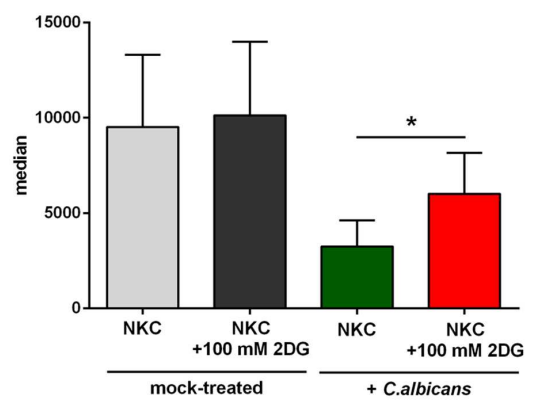

CD107a

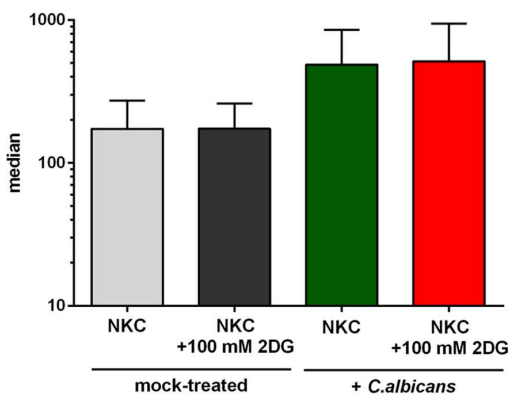

NKC

NKC

$+100 \mathrm{mM}$ 2DG

$\mathrm{NKC}+\mathrm{C}$.albicans

$\mathrm{NKC}+\mathrm{C}$.albicans

$+100 \mathrm{mM} 2 \mathrm{DG}$

B

Perforin

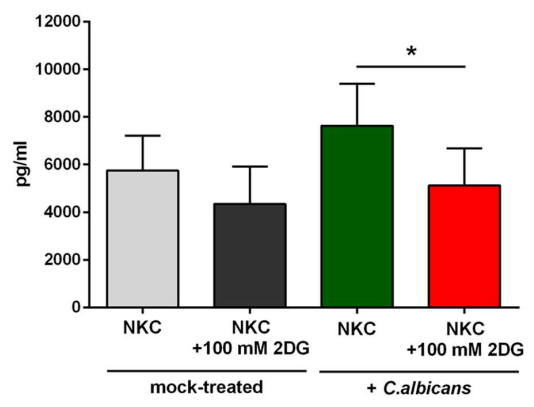

IFN- $\gamma$

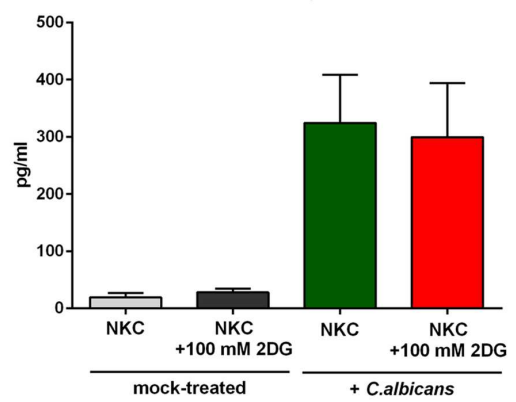

GM-CSF

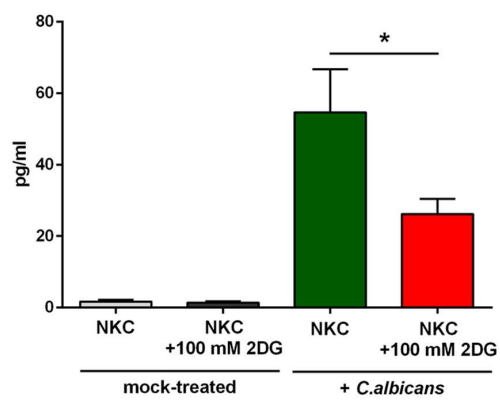

TNF- $\alpha$

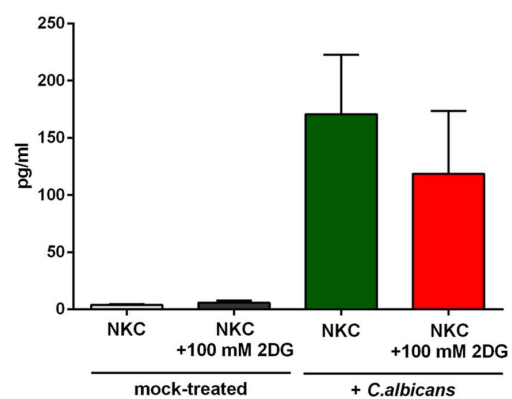

FIGURE 5 | Blockage of glycolysis has selectively effects on NK cell activation induced by $\mathbf{C}$. albicans. Human NK cells were either pre-incubated in media alone or treated with the glycolysis inhibitor 2-DG $(100 \mathrm{mM})$ for $30 \mathrm{~min}$ prior to inoculation of $\mathrm{C}$. albicans for $4 \mathrm{~h}$ to investigate the impact of glycolysis on NK cell activation. Samples were compared to mock-infected NK cells in the absence or presence of $100 \mathrm{mM}$ 2-DG. (A) NK cell activation is shown $4 \mathrm{~h}$ after inoculation of C. albicans by changes in surface expression levels of the activation markers CD16 and CD107a. Light gray filled (non-treated) and black open histograms (2-DG-treated) indicate basal expression on NK cells from mock-infected samples. Green open histograms indicate surface levels on C. albicans-infected 


\section{FIGURE 5 | Continued}

NK cells in the absence of 2-DG, red open histograms show 2-DG-treated NK cells following C. albicans infection. Data from one of seven independent experiments with virtually identical results are shown. Quantitative analysis was performed for both surface markers. Data shown are mean \pm standard deviation. CD16 revealed significantly different surface levels on NK cells after contact with C. albicans when glycolysis was blocked (red bar). (B) Supernatants of NK cell infection experiments were analyzed for secretion of perforin, GM-CSF, IFN- $\gamma$ and TNF- $\alpha$. Mock-infected NK cells in the absence (light gray bars) and presence of 2-DG (dark gray bars) were compared to $C$. albicans-infected NK cells without (green bars) and with glycolysis blockage (red bars). Bars show mean \pm standard deviation of at least three independent experiments with NK cells from different donors. Estimation of $p$-values was performed with unpaired, two-sided Student's $t$-test and asterisks indicate significance, ${ }^{*} p \leq 0.05$

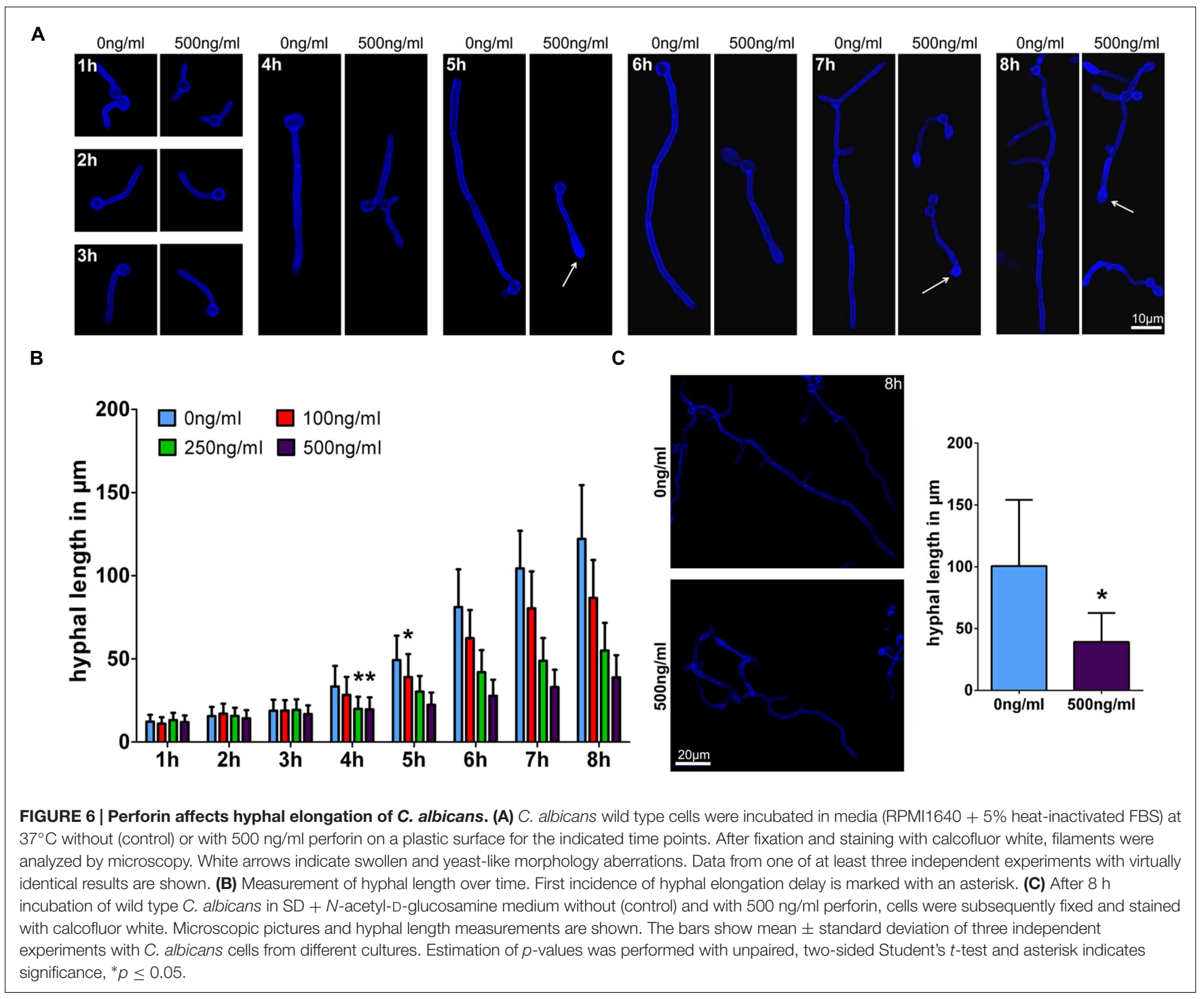

The expression of the latter gene was confirmed by qRT PCR (Figure 7C).

At the $8 \mathrm{~h}$ time point we found a strong down regulation of MAL31, which is known to have an increased expression in HIV positive patients with oral candidosis (Zakikhany et al., 2007, Figure 7B; Supplementary Table S3). The most strongly downregulated gene at this time point was FDH1 (Figure 7B), encoding for a formate dehydrogenase. This gene was described to be repressed in yeast, but not hyphal cells (Doedt et al., 2004). Thus, its down-regulation might be a transcriptional correspondent to the perforin-induced lack of hyphal elongation. However, the majority of the previously defined core filamentation response genes (Martin et al., 2013) showed no changes compared to the control medium. The only exception was orf19.2457, with a slight down-regulation at the $4 \mathrm{~h}$ time point (Supplementary Table S3). Nonetheless, we did observe an up-regulation of hyphal growth repressor gene NRG1 at $4 \mathrm{~h}$, but not for the earlier and later time points (Supplementary Table S3). The up-regulation of the yeast cell-associated SOD4 gene as well as the down-regulation of the aforementioned FDH1 might 
A

\section{up-regulated genes}

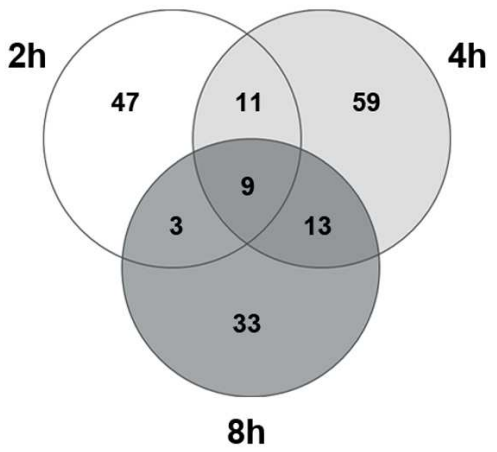

down-regulated genes

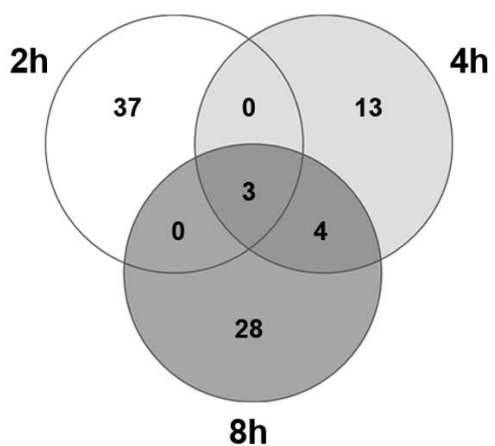

B

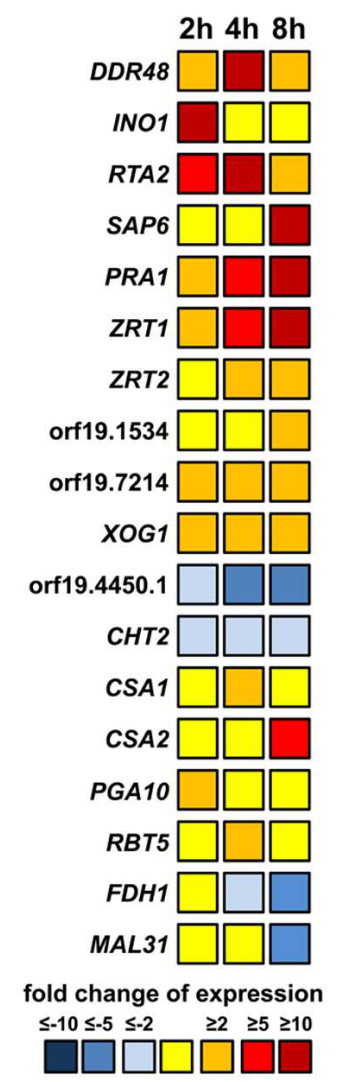

C

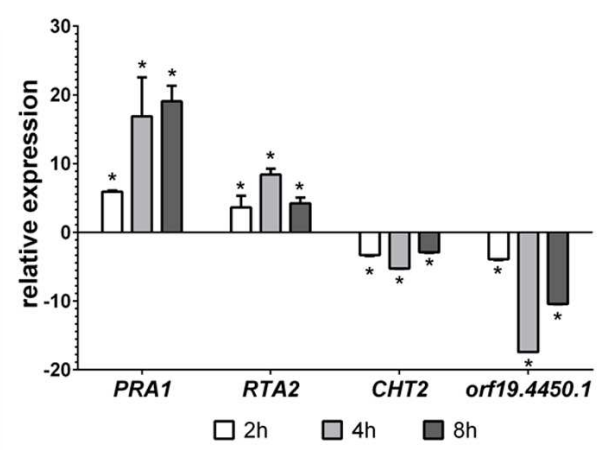

D

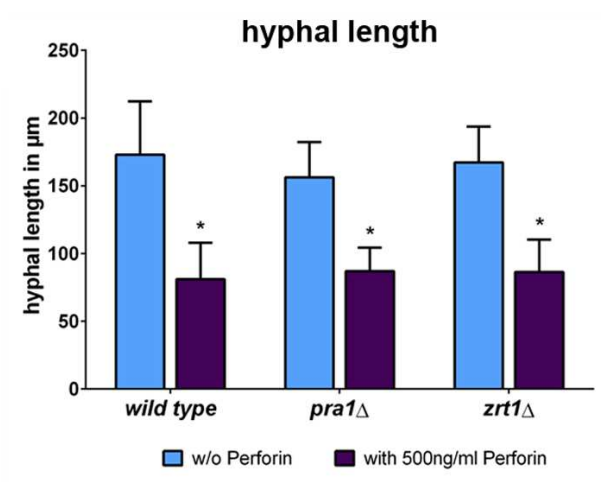

FIGURE 7 | Transcriptomic response of C. albicans to perforin shows an up-regulation of zinc homoeostasis-associated genes. (A) The number of genes differentially expressed at least with a twofold change $(p<0.05)$ after treatment with perforin are shown in Venn diagrams for the three time points. (B) Dynamics of selected genes during the treatment with perforin. (C) qRT-PCR for four selected genes from B. Shown is the fold change of expression in media containing $500 \mathrm{ng} / \mathrm{ml}$ perforin compared to media alone. (D) C. albicans wild type and mutants lacking PRA1 and ZRT1 were grown at $37^{\circ} \mathrm{C}$ for $8 \mathrm{~h}$ without or with $500 \mathrm{ng} / \mathrm{ml}$ perforin. The hyphal length in all three strains is shown. The bars show mean \pm standard deviation of three independent experiments with $C$. albicans cells from different cultures. Estimation of $p$-values was performed with unpaired, two-sided Student's $t$-test and asterisks indicate significance, ${ }^{*} p \leq 0.05$.

indicate that a transcriptional transition from hyphal to yeast cell programs starting after $8 \mathrm{~h}$.

\section{DISCUSSION}

Accumulating evidence suggests that NK cells are directly involved in antifungal immune responses. In animal models, depletion of NK cells resulted in enhanced fungal burden during C. neoformans infection, whereas adoptive transfer of NK cells mediated clearance of this fungal pathogen (Hidore and Murphy, 1986a,b; Schmidt et al., 2013). Reduced recruitment of NK cells to the infected lung in invasive aspergillosis due to depletion of MCP-1 (CCL2) resulted in a twofold greater mortality and increased fungal burden. Similarly, direct depletion of NK cells resulted in impaired protection and higher mortality (Morrison et al., 2003). For C. albicans systemic infection, depletion of NK cells has been shown to exert different effects depending on the host immune status. Depletion of NK cells in immunocompetent mice did not increase susceptibility to systemic candidiasis. On the contrary, NK cell-depleted mice were even found to be protected as a consequence of attenuated inflammation. However, depletion of NK cells in T/B/NK cell-deficient mice resulted in increased susceptibility to systemic $C$. albicans infection, which may point to an essential contribution of NK cells in immunocompromised hosts (Quintin et al., 2014). With NKp30 a unique NK cell receptor recognizing fungal pathogens has been identified (Li et al., 2013) and for most fungal pathogens analyzed so far, perforin seems to be the major mediator of NK cell mediated antifungal activity. The latter observation is amended by our analysis showing that perforin inhibits filamentation of $C$. albicans in a time and dose dependent manner and induces specific transcriptome adaptation in C. albicans. Currently it remains unclear to which extent direct antifungal activity of NK cells contributes to protective antifungal immunity, as NK cells are also an important source of both regulatory and pro-inflammatory mediators modulating other immune cells. Thus indirect effects 
of NK cells, e.g., on neutrophils or dendritic cells are likely an essential part of their role in the antifungal response network (Voigt et al., 2014). In the present study we have analyzed transcriptomic changes in NK cells after contact with C. albicans. Primary NK cells were analyzed in comparison to cytokine activated NK cells to reveal the full pattern of potential NK cell responses. These analyses revealed no qualitative differences between both cell types but suggested a more pronounced response of pre-activated cells to the fungal pathogen. KEGG analysis of differentially regulated genes highlighted the role of cytokine-cytokine receptor interactions in C. albicans activated NK cells. Among the genes found to be up-regulated were IFN$\gamma$, GM-CSF, TNF- $\alpha$, and MIP-1 $\beta$ (CCL4). Many studies in the past have further shown that NK specific cytokines such as IFN- $\gamma$ and TNF- $\alpha$ can play an important role during Candida infections (Djeu et al., 1986, 1988; Ferrante, 1989; Maródi et al., 1993). Our findings further corroborate the immunomodulatory potential of NK cells via secretion of cytokines (Ferrante, 1989; Costantini et al., 2010). Up-regulation of components of the MAPK signaling pathway indicated an activation of the immune cells, as this signaling pathway is known to contribute to NK cell cytotoxicity (MacFarlane and Campbell, 2006). In response to the confrontation with $C$. albicans, primary and cytokine activated NK cells up-regulated several genes encoding key enzymes of the glycolysis. It has been shown that glycolytic metabolism is crucial for development and function of $\mathrm{NK}$ cells (Marcais et al., 2014). Indeed, glycolysis is important for several lymphocyte populations and is integrally linked to their differentiation and function (Donnelly and Finlay, 2015). Cytokine dependent activation of NK cells correlated with a glycolytic reprogramming, which triggered the up-regulation of glycolytic enzymes and glucose transporters (Donnelly et al., 2014). The major effector molecules of NK cells, perforin and granzyme B can also be regulated by glycolytic reprogramming (Finlay et al., 2012; Donnelly et al., 2014; Marcais et al., 2014). Indeed, experiments using the glycolysis inhibitor 2-DG in the confrontation of NK cells with C. albicans clearly showed that inhibition of glycolysis reduces down-regulation of CD16 and release of perforin and GM-CSF. In contrast, no effects of 2-DG could be detected for up-regulation of CD107a and release of IFN- $\gamma$, indicating specific contributions of glycolysis to NK cell activation. This is in line with data showing that glycolysis dependent NK cell activation is dependent on the mTORC1 signaling pathway (Donnelly et al., 2014; Marcais et al., 2014). Within our transcriptome data we observed an upregulation of genes encoding for c-Myc and hypoxia-inducible factor $1 \alpha(\mathrm{HIF} 1 \alpha)$ in $C$. albicans infected cytokine activated $\mathrm{NK}$ cells, both transcription factors controlled by mTORC1 that regulate the expression of multiple glycolytic enzymes (Finlay, 2015). Together with the c-Myc transcription factor, mTORC1 is also involved in glycolytic activation in $\mathrm{T}$ cells and B lymphocytes (Wang et al., 2011; Powell et al., 2012; Sinclair et al., 2013; Caro-Maldonado et al., 2014; Oestreich et al., 2014; Donnelly and Finlay, 2015). We have not yet addressed the NK cell receptor(s) that are responsible for mediating C. albicans induced activation. However, a recent study identified NK cell receptor NKp30 to be responsible for fungal recognition and killing (Li et al., 2013). As activation of NKp30 is required for perforin release in response to fungal pathogens and blocking of glycolysis also resulted in diminished secretion of perforin in our experiments (see Figure 5), NKp30 signaling might be involved in regulation of glycolysis during Candida infection.

As perforin is the major secreted NK cell protein (Voigt et al., 2014), it was subject of a more detailed analysis focusing on its consequences for the fungal pathogen. Exposure to perforin led to a concentration dependent growth arrest during hyphal elongation. The fungal transcriptomic response was characterized by up-regulation of genes involved in zinc homeostasis (PRA1, ZRT1, ZRT2, ZRT3). So far, two of these genes were shown to be crucial to sequester environmental zinc (Citiulo et al., 2012). However, neither a pra1 $\Delta$ nor a $z$ rt1 $\Delta$ mutant responded different from wild type when confronted with perforin. On the other hand, several works from the past indicate that zinc could indeed be helpful for the fungus to encounter the effects of perforin. Decades ago it was shown that zinc can inhibit the functions of streptolysins (Avigad and Bernheimer, 1978). As streptolysins and perforin share structural and functional similarities (Gilbert, 2010), it is possible that zinc can also prevent the negative effects of perforin treatment. Additionally, zinc ions participate in the closure of cytolysin-caused channels in Lettre cells (Bashford et al., 1988) or pores formed from either alphahemolysin (Walker et al., 1995) or pneumolysin (Franco-Vidal et al., 2008). Based on these previous results, we suggest that zinc homeostasis might be involved in the response of $C$. albicans to perforin treatment, although the details remain to be elucidated. In addition to zinc homeostatis, genes involved in the heme/hemoglobin iron utilization were found to be up-regulated although to a lesser extent than the zinc-associated genes. Transcript levels of CSA2 were highly increased at the $8 \mathrm{~h}$ time point. The strong induction of the gene might be linked to perforin-induced reduction of iron availability, especially as Csa2 is speculated to act as a kind of "hemophore" (Crawford and Wilson, 2015). However, CSA2 was also shown to be up-regulated in response to other stressful environments, for example the presence of nitric oxide (Hromatka et al., 2005). The most down-regulated gene during co-incubation with perforin at all three time points was orf19.4450.1. The gene encodes a small protein of 68 amino acids without known function. However, previous transcriptome studies showed an up-regulation of the gene transcript during fungal growth in the intestinal tract and biofilm formation (Rosenbach et al., 2010; Bonhomme et al., 2011), which is in line with the reduced gene expression of orf19.4450.1 during perforin-induced inhibition of C. albicans filamentation.

Taken together, our data confirm activation of NK cells by C. albicans and show that beside functional activation metabolic adaptation takes place by increased glycolysis. Furthermore we describe the induction of a bona fide zinc depletion response in a fungal pathogen after exposure to perforin, suggesting a potential link of perforin action to this essential micronutrient. 


\section{AUTHOR CONTRIBUTIONS}

$\mathrm{DH}, \mathrm{JV}, \mathrm{KH}, \mathrm{MB}, \mathrm{RM}$ performed experiments; SB contributed reagents and mutants; DA-E, MW analyzed data; KH, JL, RM, OK designed experiments and planned study; DH, JV, KH, RM, OK wrote the manuscript; MB, JL, DA-E, MW, SB critically revised the manuscript; $\mathrm{DH}$ and JV contributed equally to this manuscript.

\section{FUNDING}

This work was financed by the Deutsche Forschungsgemeinschaft (DFG) within the Collaborative Research Center CRC124 FungiNet (projects A2 to JL and $\mathrm{C} 3$ to $\mathrm{OK}$ ) and the German Ministry for Education and Science in the program Unternehmen Region (BMBF 03Z2JN21 to OK).

\section{REFERENCES}

Albisetti, M., Lauener, R. P., Güngör, T., Schär, G., Niggli, F. K., and Nadal, D. (2004). Disseminated Fusarium oxysporum infection in hemophagocytic lymphohistiocytosis. Infection 32, 364-366. doi: 10.1007/s15010-004-3135-8

Avigad, L. S., and Bernheimer, A. W. (1978). Inhibition of hemolysis by zinc and its reversal by L-histidine. Infect. Immun. 19, 1101-1103.

Bashford, C. L., Menestrina, G., Henkart, P. A., and Pasternak, C. A. (1988). Cell damage by cytolysin. Spontaneous recovery and reversible inhibition by divalent cations. J. Immunol. 141:39.

Bonhomme, J., Chauvel, M., Goyard, S., Roux, P., Rossignol, T., and d'Enfert, C. (2011). Contribution of the glycolytic flux and hypoxia adaptation to efficient biofilm formation by Candida albicans. Mol. Microbiol. 80, 995-1013. doi: 10.1111/j.1365-2958.2011.07626.x

Bouzani, M., Ok, M., Mccormick, A., Ebel, F., Kurzai, O., Morton, C. O., et al. (2011). Human NK cells display important antifungal activity against Aspergillus fumigatus, which is directly mediated by IFN-gamma release. J. Immunol. 187, 1369-1376. doi: 10.4049/jimmunol.1003593

Caro-Maldonado, A., Wang, R., Nichols, A. G., Kuraoka, M., Milasta, S., Sun, L. D., et al. (2014). Metabolic reprogramming is required for antibody production that is suppressed in anergic but exaggerated in chronically BAFF-exposed B cells. J. Immunol. 192, 3626-3636. doi: 10.4049/jimmunol.1302062

Citiulo, F., Jacobsen, I. D., Miramon, P., Schild, L., Brunke, S., Zipfel, P., et al. (2012). Candida albicans scavenges host zinc via Pral during endothelial invasion. PLoS Pathog. 8:e1002777. doi: 10.1371/journal.ppat.1002777

Costantini, C., Micheletti, A., Calzetti, F., Perbellini, O., Pizzolo, G., and Cassatella, M. A. (2010). Neutrophil activation and survival are modulated by interaction with NK cells. Int. Immunol. 22, 827-838. doi: 10.1093/intimm/dxq434

Crawford, A., and Wilson, D. (2015). Essential metals at the host-pathogen interface: nutritional immunity and micronutrient assimilation by human fungal pathogens. FEMS Yeast Res. 15:fov071. doi: 10.1093/femsyr/fov071

Djeu, J. Y., Blanchard, D. K., Halkias, D., and Friedman, H. (1986). Growth inhibition of Candida albicans by human polymorphonuclear neutrophils: activation by interferon-gamma and tumor necrosis factor. J. Immunol. 137, 2980-2984.

Djeu, J. Y., Blanchard, D. K., Richards, A. L., and Friedman, H. (1988). Tumor necrosis factor induction by Candida albicans from human natural killer cells and monocytes. J. Immunol. 141, 4047-4052.

Doedt, T., Krishnamurthy, S., Bockmuhl, D. P., Tebarth, B., Stempel, C., Russell, C. L., et al. (2004). APSES proteins regulate morphogenesis and metabolism in Candida albicans. Mol. Biol. Cell 15, 3167-3180. doi: 10.1091/10.1091/mbc.E0311-0782

Donnelly, R. P., and Finlay, D. K. (2015). Glucose, glycolysis and lymphocyte responses. Mol. Immunol. 68(2Pt C), 513-519. doi: 10.1016/j.molimm.2015.07.034

\section{ACKNOWLEDGMENTS}

We gratefully acknowledge all volunteers who donated blood for this study. In addition, we wish to thank Anna-Lena Schmitt, Cindy Reichmann and Toni Kaulfuß for technical assistance.

\section{SUPPLEMENTARY MATERIAL}

The Supplementary Material for this article can be found online at: http://journal.frontiersin.org/article/10.3389/fmicb. 2016.00750

TABLE S2 | Differentially expressed genes of primary and cytokine activated NK cells confronted with $C$. albicans.

TABLE S3 | Differentially expressed genes of perforin-treated C. albicans.

Donnelly, R. P., Loftus, R. M., Keating, S. E., Liou, K. T., Biron, C. A., Gardiner, C. M., et al. (2014). mTORC1-dependent metabolic reprogramming is a prerequisite for NK cell effector function. J. Immunol. 193, 4477-4484. doi: 10.4049/jimmunol.1401558

Duggan, S., Leonhardt, I., Hunniger, K., and Kurzai, O. (2015). Host response to Candida albicans bloodstream infection and sepsis. Virulence 6, 316-326. doi: $10.4161 / 21505594.2014 .988096$

Elsasser, T. H., and Kahl, S. (2002). Adrenomedullin has multiple roles in disease stress: development and remission of the inflammatory response. Microsc. Res. Technol. 57, 120-129. doi: 10.1002/jemt.10058

Ferrante, A. (1989). Tumor necrosis factor alpha potentiates neutrophil antimicrobial activity: increased fungicidal activity against Torulopsis glabrata and Candida albicans and associated increases in oxygen radical production and lysosomal enzyme release. Infect. Immun. 57, 2115-2122.

Finlay, D. K. (2015). Metabolic regulation of natural killer cells. Biochem. Soc. Trans. 43, 758-762. doi: 10.1042/BST20150116

Finlay, D. K., Rosenzweig, E., Sinclair, L. V., Feijoo-Carnero, C., Hukelmann, J. L., Rolf, J., et al. (2012). PDK1 regulation of mTOR and hypoxia-inducible factor 1 integrate metabolism and migration of CD8+ T cells. J. Exp. Med. 209, 2441-2453. doi: 10.1084/jem.20112607

Franco-Vidal, V., Beurg, M., Darrouzet, V., Bebear, J. P., Skinner, L. J., and Dulon, D. (2008). Zinc protection against pneumolysin toxicity on rat cochlear hair cells. Audiol. Neurootol. 13, 65-70. doi: 10.1159/000108763

Gilbert, R. J. (2010). Cholesterol-dependent cytolysins. Adv. Exp. Med. Biol. 677, 56-66. doi: 10.1007/978-1-4419-6327-7_5

Gillum, A. M., Tsay, E. Y., and Kirsch, D. R. (1984). Isolation of the Candida albicans gene for orotidine- $5^{\prime}$-phosphate decarboxylase by complementation of S. cerevisiae ura3 and E. coli pyrF mutations. Mol. Gen. Genet. 198, 179-182. doi: 10.1007/BF00328721

Hidore, M. R., and Murphy, J. W. (1986a). Correlation of natural killer cell activity and clearance of Cryptococcus neoformans from mice after adoptive transfer of splenic nylon wool-nonadherent cells. Infect. Immun. 51, 547-555.

Hidore, M. R., and Murphy, J. W. (1986b). Natural cellular resistance of beige mice against Cryptococcus neoformans. J. Immunol. 137, 3624-3631.

Hromatka, B. S., Noble, S. M., and Johnson, A. D. (2005). Transcriptional response of Candida albicans to nitric oxide and the role of the YHB1 gene in nitrosative stress and virulence. Mol. Biol. Cell 16, 4814-4826. doi: 10.1091/mbc.E05-050435

Jimenez, B. E., and Murphy, J. W. (1984). In vitro effects of natural killer cells against Paracoccidioides brasiliensis yeast phase. Infect. Immun. 46, 552-558.

Lanier, L. L. (2008). Up on the tightrope: natural killer cell activation and inhibition. Nat. Immunol. 9, 495-502. doi: 10.1038/ni1581

Lei, Y., and Takahama, Y. (2012). XCL1 and XCR1 in the immune system. Microbes Infect. 14, 262-267. doi: 10.1016/j.micinf.2011.10.003 
Levitz, S. M., Dupont, M. P., and Smail, E. H. (1994). Direct activity of human T lymphocytes and natural killer cells against Cryptococcus neoformans. Infect. Immun. 62, 194-202.

Li, S. S., Kyei, S. K., Timm-McCann, M., Ogbomo, H., Jones, G. J., Shi, M., et al. (2013). The NK receptor NKp30 mediates direct fungal recognition and killing and is diminished in NK cells from HIV-infected patients. Cell Host Microbe 14, 387-397. doi: 10.1016/j.chom.2013.09.007

Lipscomb, M. F., Alvarellos, T., Toews, G. B., Tompkins, R., Evans, Z., Koo, G., et al. (1987). Role of natural killer cells in resistance to Cryptococcus neoformans infections in mice. Am. J. Pathol. 128, 354-361.

Ma, L. L., Wang, C. L., Neely, G. G., Epelman, S., Krensky, A. M., and Mody, C. H. (2004). NK cells use perforin rather than granulysin for anticryptococcal activity. J. Immunol. 173, 3357-3365. doi: 10.4049/jimmunol.173.5.3357

MacFarlane, A. W. T., and Campbell, K. S. (2006). Signal transduction in natural killer cells. Curr. Top. Microbiol. Immunol. 298, 23-57.

Marcais, A., Cherfils-Vicini, J., Viant, C., Degouve, S., Viel, S., Fenis, A., et al. (2014). The metabolic checkpoint kinase mTOR is essential for IL-15 signaling during the development and activation of NK cells. Nat. Immunol. 15, 749-757. doi: 10.1038/ni.2936

Maródi, L., Schreiber, S., Anderson, D. C., MacDermott, R. P., Korchak, H. M., and Johnston, R. B. Jr. (1993). Enhancement of macrophage candidacidal activity by interferon-gamma. Increased phagocytosis, killing, and calcium signal mediated by a decreased number of mannose receptors. J. Clin. Invest. 91, 2596-2601. doi: 10.1172/JCI116498

Martin, R., Albrecht-Eckardt, D., Brunke, S., Hube, B., Hunniger, K., and Kurzai, O. (2013). A core filamentation response network in Candida albicans is restricted to eight genes. PLoS ONE 8:e58613. doi: 10.1371/journal.pone.0058613

Martin, R., Moran, G. P., Jacobsen, I. D., Heyken, A., Domey, J., Sullivan, D. J., et al. (2011). The Candida albicans-specific gene EED1 encodes a key regulator of hyphal extension. PLoS ONE 6:e18394. doi: 10.1371/journal.pone.0018394

Martinet, L., and Smyth, M. J. (2015). Balancing natural killer cell activation through paired receptors. Nat. Rev. Immunol. 15, 243-254. doi: 10.1038/nri3799

Morrison, B. E., Park, S. J., Mooney, J. M., and Mehrad, B. (2003). Chemokine-mediated recruitment of NK cells is a critical host defense mechanism in invasive aspergillosis. J. Clin. Invest. 112, 1862-1870. doi: 10.1172/JCI200318125

Oestreich, K. J., Read, K. A., Gilbertson, S. E., Hough, K. P., Mcdonald, P. W., Krishnamoorthy, V., et al. (2014). Bcl-6 directly represses the gene program of the glycolysis pathway. Nat. Immunol. 15, 957-964. doi: 10.1038/ni.2985

Petkus, A. F., and Baum, L. L. (1987). Natural killer cell inhibition of young spherules and endospores of Coccidioides immitis. J. Immunol. 139, 3107-3111.

Pfaffl, M. W. (2001). A new mathematical model for relative quantification in real-time RT-PCR. Nucleic Acids Res. 29:e45. doi: 10.1093/nar/29.9.e45

Powell, J. D., Pollizzi, K. N., Heikamp, E. B., and Horton, M. R. (2012). Regulation of immune responses by mTOR. Annu. Rev. Immunol. 30, 39-68. doi: 10.1146/annurev-immunol-020711-075024

Quintin, J., Voigt, J., Van Der Voort, R., Jacobsen, I. D., Verschueren, I., Hube, B., et al. (2014). Differential role of NK cells against Candida albicans infection in immunocompetent or immunocompromised mice. Eur. J. Immunol. 44, 2405-2414. doi: 10.1002/eji.201343828

Rosenbach, A., Dignard, D., Pierce, J. V., Whiteway, M., and Kumamoto, C. A. (2010). Adaptations of Candida albicans for growth in the mammalian intestinal tract. Eukaryot. Cell 9, 1075-1086. doi: 10.1128/EC.00034-10
Schmidt, S., Schneider, A., Demir, A., Lass-Florl, C., and Lehrnbecher, T. (2015). Natural killer cell-mediated damage of clinical isolates of mucormycetes. Mycoses 59, 34-38. doi: 10.1111/myc.12431

Schmidt, S., Tramsen, L., Hanisch, M., Latge, J. P., Huenecke, S., Koehl, U., et al. (2011). Human natural killer cells exhibit direct activity against Aspergillus fumigatus hyphae, but not against resting conidia. J. Infect. Dis. 203, 430-435. doi: 10.1093/infdis/jiq062

Schmidt, S., Zimmermann, S. Y., Tramsen, L., Koehl, U., and Lehrnbecher, T. (2013). Natural killer cells and antifungal host response. Clin. Vaccine Immunol. 20, 452-458. doi: 10.1128/CVI.00606-12

Schulz-Knappe, P., Magert, H. J., Dewald, B., Meyer, M., Cetin, Y., Kubbies, M., et al. (1996). HCC-1, a novel chemokine from human plasma. J. Exp. Med. 183, 295-299. doi: 10.1084/jem.183.1.295

Sinclair, L. V., Rolf, J., Emslie, E., Shi, Y. B., Taylor, P. M., and Cantrell, D. A. (2013). Control of amino-acid transport by antigen receptors coordinates the metabolic reprogramming essential for T cell differentiation. Nat. Immunol. 14, 500-508. doi: $10.1038 /$ ni.2556

Sung, L., Weitzman, S. S., Petric, M., and King, S. M. (2001). The role of infections in primary hemophagocytic lymphohistiocytosis: a case series and review of the literature. Clin. Infect. Dis. 33, 1644-1648. doi: 10.1086/323675

Voigt, J., Hunniger, K., Bouzani, M., Jacobsen, I. D., Barz, D., Hube, B., et al. (2014). Human natural killer cells acting as phagocytes against Candida albicans and mounting an inflammatory response that modulates neutrophil antifungal activity. J. Infect. Dis. 209, 616-626. doi: 10.1093/infdis/jit574

Voskoboinik, I., Whisstock, J. C., and Trapani, J. A. (2015). Perforin and granzymes: function, dysfunction and human pathology. Nat. Rev. Immunol. 15, 388-400. doi: 10.1038/nri3839

Waddell, S. J., Butcher, P. D., and Stoker, N. G. (2007). RNA profiling in host-pathogen interactions. Curr. Opin. Microbiol. 10, 297-302. doi: 10.1016/j.mib.2007.05.013

Walker, B., Braha, O., Cheley, S., and Bayley, H. (1995). An intermediate in the assembly of a pore-forming protein trapped with a genetically-engineered switch. Chem. Biol. 2, 99-105. doi: 10.1016/1074-5521(95)90282-1

Wang, R., Dillon, C. P., Shi, L. Z., Milasta, S., Carter, R., Finkelstein, D., et al. (2011). The transcription factor Myc controls metabolic reprogramming upon $\mathrm{T}$ lymphocyte activation. Immunity 35, 871-882. doi: 10.1016/j.immuni.2011.09.021

Zakikhany, K., Naglik, J. R., Schmidt-Westhausen, A., Holland, G., Schaller, M., and Hube, B. (2007). In vivo transcript profiling of Candida albicans identifies a gene essential for interepithelial dissemination. Cell Microbiol. 9, 2938-2954. doi: 10.1111/j.1462-5822.2007.01009.x

Conflict of Interest Statement: The authors declare that the research was conducted in the absence of any commercial or financial relationships that could be construed as a potential conflict of interest.

Copyright (C) 2016 Hellwig, Voigt, Bouzani, Löffler, Albrecht-Eckardt, Weber, Brunke, Martin, Kurzai and Hünniger. This is an open-access article distributed under the terms of the Creative Commons Attribution License (CC BY). The use, distribution or reproduction in other forums is permitted, provided the original author(s) or licensor are credited and that the original publication in this journal is cited, in accordance with accepted academic practice. No use, distribution or reproduction is permitted which does not comply with these terms. 